\title{
The Long-Term Effects of Outdoor Air Pollution in Urban Environments on Cardiovascular Health: A Global Review
}

\author{
LINDSAY KRAUS ${ }^{1}$; HEATHER M. MURPHY, PHD ${ }^{1}$ \\ ${ }^{1}$ Department of Epidemiology and Biostatistics, College of Public Health, Temple University \\ Correspondence: tuj16109@,temple.edu (Lindsay Kraus)
}

The effects of air pollution on health are listed as a significant cause of death worldwide. Slightly over 3 million deaths per year are due to outdoor air pollution. Studies have shown that short-term increases in exposure to particulate matter have increased the risk of cardiovascular diseases such as myocardial infarction, stroke, and beart failure. However, less is known about the longer-term effects of air pollution on various cardiovascular diseases. The American Heart Association formally recognized PM2.5 as a significant cardiovascular risk factor in 2010. Since then, more prolonged-term exposure to air pollution has been suggested to cause chronic cardiometabolic and cardiovascular problems. The effects of long-term (>1 year) air pollution are significant, but not as much is known about how location affects this exposure. Associations with cardiovascular diseases and their risk factors are often increased in urban settings, which is attributed to a bigher concentrations of outdoor air pollution. Potential causes of long-term air pollution concentrations in cities or metropolitan areas come from traffic exposure and traffic intensity. The U.S. Environmental Protection Agency and United Nations have suggested changes in air quality standards, implementation plans, and ways to reduce vehicle emissions specifically to improve buman bealth and reduce the adverse effects of air pollution; however, more work still needs to be done. This review assesses the impact of the global long-term (>1 year) air pollution exposure, specifically in urban environments on cardiovascular health and disease.

Keywords: Long-term air pollution, Cardiovascular disease, Pollution exposure

\section{Introduction}

Air pollution is a major global problem. The effect of air pollution has been directly associated with the exacerbated climate crisis as well as detrimental increases in our global public health. The threat of air pollution on health has been listed as a significant cause of death worldwide. ${ }^{1,2}$ Over 3 million deaths per year are due to particulate matter less than $2.5 \mathrm{uM}$ or $\mathrm{PM}_{2 .}{ }^{3}$ Air pollution will only increase over time due to the drastic increase in energy production, transportation, waste accumulation, and natural disasters like forest fires ${ }^{2,3}$, all of which stress the importance of addressing the health concerns associated with this pollution.

Air pollution is defined as a heterogeneous mixture of gases, liquids, and particulate matter (PM) that is mostly derived from combustion, specifically from fossil fuels. ${ }^{4}$ Location is a significant factor that must be considered when discussing air pollution. ${ }^{5}$ Urbanized areas have a higher risk of increased air pollution concentrations largely due to 
energy consumption and exhaust emissions. ${ }^{6,7,8}$ Therefore, the urban areas have a higher risk of various cardiovascular diseases (CVDs). ${ }^{4}$ The World Health Organization (WHO) has stated about $80 \%$ of people living in cities are breathing in air that is over the WHO guideline limit. ${ }^{6}$ Specifically, people from lower and middle-income countries suffer from the most exposure and, therefore, are at the highest risk of air pollution-related health risk. ${ }^{7}$ Within the U.S., $80.2 \%$ of Americans live in an urban area versus the $19.8 \%$ that live in a rural area. Interestingly, within the urban areas, $11.2 \%$ of Americans are in the lowest socioeconomic status (SES). ${ }^{9}$ Globally, the largest gap between the lowest and highest SES exists predominantly in urban settings. ${ }^{10}$

Air pollution can be created in indoor and outdoor environments, such as smoke in a house versus smog in a city, respectively. More specifically, outdoor or ambient air pollution has major implications on human health through the inhalation of toxic particles. The main sources of outdoor air pollution include particulate matter from fossil fuel combustion. ${ }^{11}$ Additionally, changes in the composition in ground-level ozone $\left(\mathrm{O}_{3}\right)$ due to industrial combustion, traffic, and gasoline can play a major role in outdoor air pollution. ${ }^{11} \mathrm{PM}$ and $\mathrm{NO} 2$ are usually the main contributors to outdoor air pollution; however, ultrafine particles (UFP) have also been associated with increased outdoor air pollution, often due to the combustion reactions ${ }^{12}$. While both outdoor and indoor air pollution are important in regards to global health, in this review, only outdoor air pollution-related to human cardiovascular health will be addressed.

The length of exposure to air pollution is an essential factor related to cardiovascular

\section{Methods}

This scoping literature review used articles found through the PubMed and Google Scholar databases to answer the initial question, "how does long-term outdoor air pollution found in urban environments affect cardiovascular health?" The initial search examined keywords displayed in Table 1 found health as well. Studies have found that shortterm increases in exposure to increased concentrations of particulate matter have amplified the risk of cardiovascular diseases such as myocardial infarction, stroke, heart failure, etc.. ${ }^{9}$ It is known that high amounts of ambient $\mathrm{PM}_{2.5}$ increase the risk of CVD, specifically in highly urbanized areas, even in short amounts of exposure time ${ }^{13}$, indicating the necessity to fully understand the effect longterm. Specifically, a short-term exposure to outdoor air pollution was strongly associated with the risk factors of ischemic heart disease, specifically in cities ${ }^{1415}$ Other health risks may also intensify the risk of susceptibility to air pollution and CVDs, such as obesity. ${ }^{16}$

However, until recently, less was known about the sizeable impact long-term air pollution has on cardiovascular health. The American Heart Association (AHA) formally recognized $\mathrm{PM}_{2.5}$ as a major cardiovascular risk factor in $2010 .{ }^{10}$ Since then, long-term exposure to air pollution has been suggested to cause chronic cardiometabolic problems such as diabetes. ${ }^{11}$ However, there is still a lack of information on the effect of long-term outdoor air pollution on cardiovascular health, specifically in urban locations such as cities or metropolitan areas with higher concentrations of air pollution.

In this review, short-term air pollution is described as less than one year of exposure, while long-term air pollution is three or more years of exposure. This review will outline the latest research from the last twenty years linking the extended exposure to air pollution in metropolitan areas to cardiovascular disease on a global scale.

in the title and abstract of retrieved papers as well as the index terms that describe the articles. All relevant reviews and articles were exported to Zotero for further examination and comparison. In the screen, all articles were scanned for titles based on the relevance of inclusion and exclusion criteria specified in 


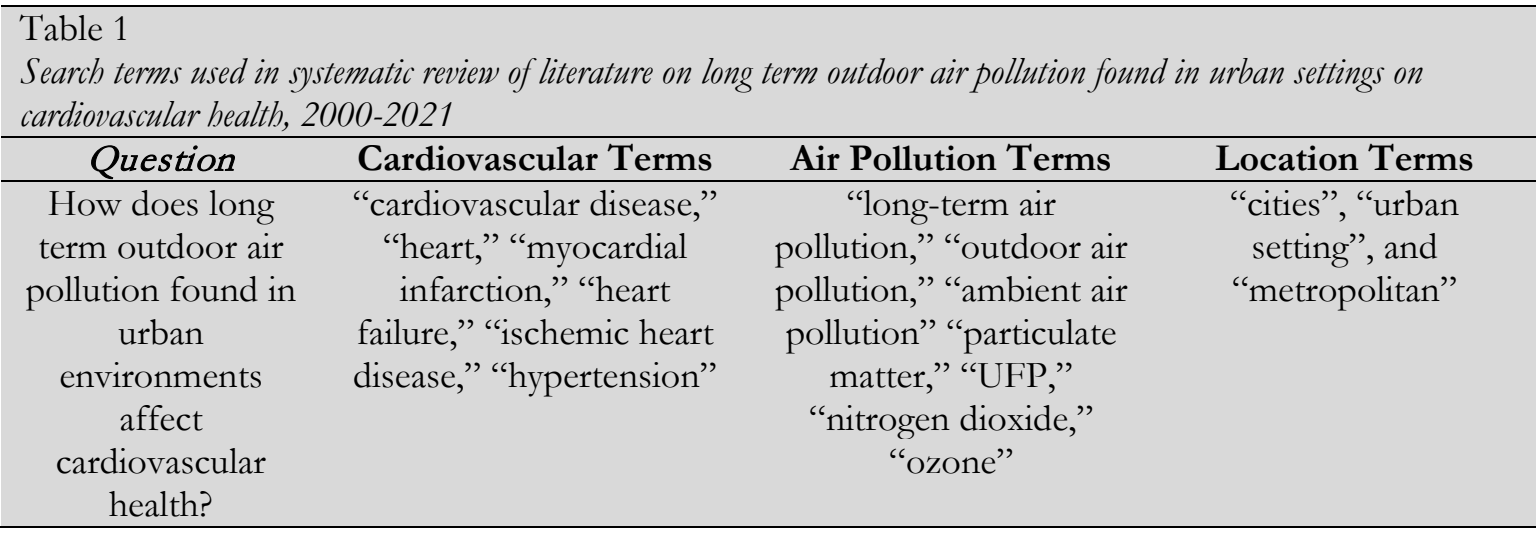

Table 2, which also helped identify our Population, Exposure, and Outcome framework. The inclusion criteria consisted of studies that took place in defined cities or metropolitan areas studying outdoor air pollution effects on cardiovascular health for greater than one year. Exclusion criteria included separate, non-cardiovascular-related health effects such as renal function, lung function, and brain function as well as suburban or non-metropolitan specific locations. Any studies that were conducted for less than one year were considered short-term exposure and were not included.

Additionally, we searched for recent articles that researched over the last thirty years to emphasize the latest long-term studies; therefore, research studies conducted between 1990 and 2021 were included. We also examined broader primary studies to help narrow our search for more recent and specific articles. We examined the reference list of these key papers to identify additional studies for more specific articles. Furthermore, to find grey literature on the topic, we individually searched for key authors in the field that were established in the original search, key agencies or organizations that often conduct relevant research, and key journals that have an index or database of related topics. Additionally, we referenced the PRISMA flowchart and checklist for a scoping literature review ${ }^{17}$. From this, a total of 9650 articles were found through database searching. After duplicates were removed and screened through titles and abstracts, approximately 173 articles were eligible. From this group, the articles were fully scanned and 59 were used for this review.

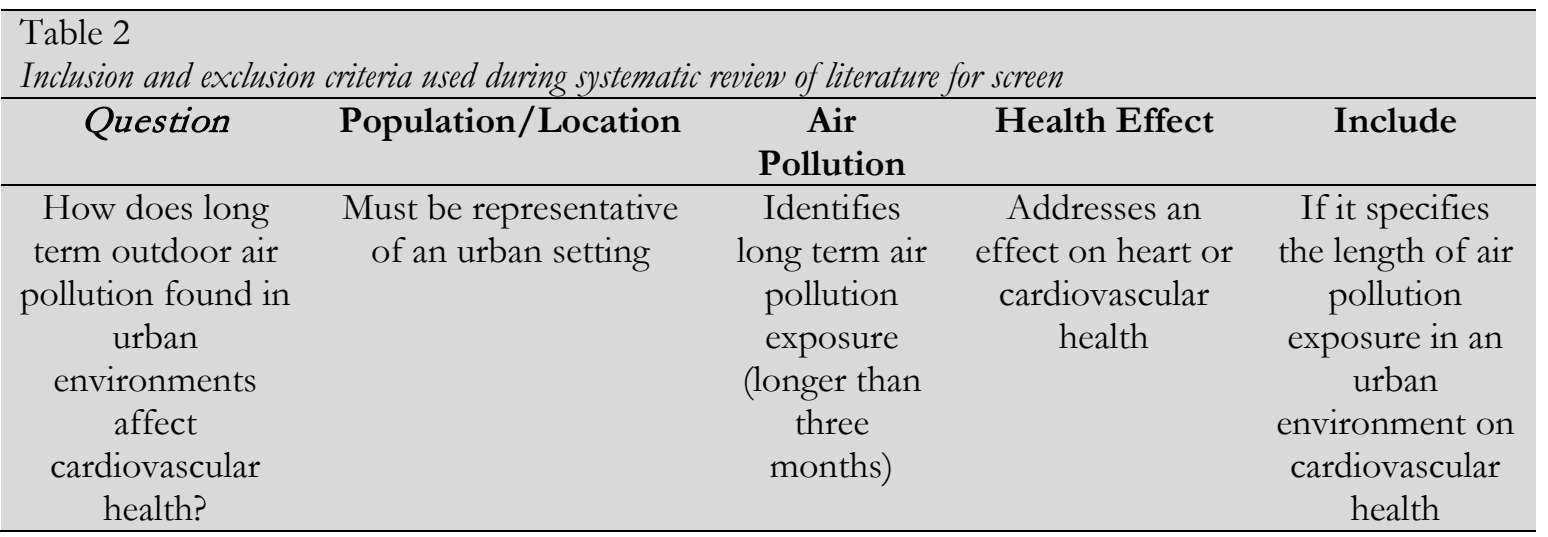




\section{Results}

\section{Long-Term Air Pollution and CVD}

Long-term exposure to $\mathrm{PM}_{2.5}$ and ozone $\left(\mathrm{O}_{3}\right)$ has been connected with the progression of CVDs. Recently, long-term exposure to air pollution resulted in increased heart rate variability, blood pressure, vascular tone, blood coagulation, and atherosclerosis..$^{18} \mathrm{~A}$ study through the AHA found that people exposed to $\mathrm{PM}_{2.5}$ and ozone over five years had poorer health one year following a myocardial infarction (MI). This was correlated with an added risk of death due to increased morbidity and mortality as well as worsened symptoms within the following five years. ${ }^{19}$ Using cohort studies, An et al.. summarized that long-term exposure to air pollution resulted in a significantly higher risk of CVD (1.24\%) compared to short-term exposure, which was hypothesized to be because of the compounding effects of extended air pollution exposure. ${ }^{18}$ Another study found that cardiopulmonary death was associated with fine PM $\left(\mathrm{PM}_{2.5}\right)$ and sulfur dioxide $\left(\mathrm{SO}_{2}\right)$ pollution. Interestingly,
Pope et al. concluded that every ten microgram increase in $\mathrm{PM}_{2.5}$ air pollution was associated with a $4 \%$ increased risk of cardiopulmonary mortality and, therefore, contributed to the adverse effects of long-term exposure on health. ${ }^{20}$

A critical study by Miller et al. found that postmenopausal women had an amplified risk of CVD and death associated with cardiovascular issues because of long-term exposure to fine PM. In addition, they found that there were different risks and exposures to women in cities. ${ }^{21}$ Another group found that the elderly community (65 years or older) are more at risk for the adverse effects of air pollution on cardiovascular health. A study of the elderly population in Taiwan found that added long-term exposure to ambient air pollution causes changes in blood pressure as well as blood sugar and blood lipids on older members of the population. ${ }^{22}$

\section{How Extended Exposure to Outdoor Air Pollution Affects Cardiovascular Health}

To better understand how to treat and prevent CVD associated with air pollution, it is essential to determine how air pollution causes an increase in disease. Some studies have explored how fine particulate air pollution causes a variety of CVDs through inflammatory mechanisms. One study examined increased pulmonary and systemic inflammation. This inflammation is associated with breathing in the particulate matter associated explicitly with air

\section{Long-term Air Pollution in Urban Settings}

The effect of long-term air pollution is significant, but not as much is known about how location affects this exposure. In cities, there is an escalation in traffic and motor emissions strongly associated with air pollution. ${ }^{25}$ This kind of air pollution often consists of elemental carbon, ultrafine particles, and nitrogen oxides. ${ }^{25}$ pollution. This escalation in the inflammation from air pollution exacerbated atherosclerosis and decreased cardiac function. ${ }^{23}$ Another group studied environmental PM in an atherosclerotic mouse model and found that long-term exposure to this air pollution changed the vascular tone and significantly increased vascular inflammation leading to a CVD such as atherosclerosis. ${ }^{24}$

An initial study found that there was a strong association of increased fine PM air pollution that led to increased mortality in six different United States cities, including Steubenville, St. Louis, Harriman, Watertown, Topeka, and Portage ${ }^{26}$. These cities were chosen because of the known air pollution in the area, with 
Steubenville being the worst and Portage being the best. Specifically, the authors found an increase in cardiopulmonary diseases in over eight thousand adults over 15 years. ${ }^{26}$ Later in 2006, a similar study found that increased $\mathrm{PM}_{2.5}$ was associated with cardiovascular mortality, and when that exposure was reduced, there was a decrease in mortality. ${ }^{27}$

High blood pressure or hypertension is a significant risk factor for CVD. ${ }^{28}$ A study found that long-term exposure to PM led to an increase in arterial blood pressure. This association was significantly amplified in urban settings, which was attributed to an increased concentration of $\mathrm{PM}_{2.5}$. This outcome was independent of ethnic groups or seasonal changes. ${ }^{29}$

Some confounding variables have been suspected in outdoor air pollution studies. Specifically, changes in season and temperature have been thought to affect air quality. ${ }^{24} \mathrm{~A}$ study examined the risk in cities over various seasons and found the risk of mortality related to outdoor air pollution was not significantly different in above-average or below-average temperatures. The risk was the same in cities in drier climates as well as humid climates. This indicated that the weather or temperature changes were not responsible for increased mortality related to air quality or condition. ${ }^{30}$

As shown in Table 3, there are various pollutants commonly found in outdoor metropolitan environments that intensify cardiovascular problems. However, Cesaroni et al. suggested that air pollutants, specifically from traffic, including $\mathrm{NO}_{2}$ and $\mathrm{PM}_{2.5}$, cause the most severe and persisting cardiovascular problems. Specifically, traffic-related air pollution is defined as $\mathrm{NO}_{2}$ and $\mathrm{PM}_{2.5}$ that is uniquely augmented during rush hour periods, and is also found in vehicular emissions. ${ }^{31}$ In Rome, the long-term exposure to air pollution was attributed to increased exposure to $\mathrm{NO}_{2}$ and $\mathrm{PM}_{2.5}$, which was associated with a greater number of incidents of ischemic heart disease. ${ }^{32}$ A similar result was also found in major cities in Greece, where CVD morbidity was associated with prolonged exposure to traffic-related air pollution. ${ }^{33}$ In a cohort study from Norway and the United Kingdom, traffic air pollution was also associated with increased cardiovascular mortality. Specifically, in high traffic areas, the long-term exposure to particulate air pollution was connected to more cases of CVD. Additionally, even air pollution levels lower than the current European air quality standards were linked to CVD risk. ${ }^{34}$ In general, air pollution in major European cities is caused by traffic pollution, which is resulting in elevated risks of CVDs. Finally, Beelen et al. created a multicenter program called European Study of Cohorts for Air Pollution Effects (ESCAPE), which assessed long-term air pollution on mortality. This study assessed large cities in Europe, some of which include Oslo, Stockholm, Augsburg, Rome, and San Sebastian, and found an increase in risk factors for cardiovascular diseases. Overall, this study summarized the massive negative effect on heart health due to air pollution in cities, specifically in Europe..$^{35}$

In the Netherlands, extended exposure to traffic-related air pollution was linked to an added risk of cardiovascular mortality. The study measured black smoke, nitric oxide, sulfur dioxide, and $\mathrm{PM}_{2.5}$. They measured local or home outdoor exposure compared to urban exposure based on geographic information systems to determine the intensity of traffic exposure in the respective areas. They discovered that traffic intensity, specifically near the home, was associated with a $10 \mathrm{ug} / \mathrm{m}^{3}$ increase in black smoke, $\mathrm{NO}$, and $\mathrm{PM}_{2.5}$, which was related to cardiovascular mortality and lung cancer. Downward et al. found that long-term exposure to ultrafine particles (UFP) was strongly associated with an increase in CVD. Specifically, the authors found that UFP was often underestimated, due to the current emphasis on PM. This long-term exposure study in Amsterdam found increased incidents of myocardial infarction as well as heart failure associated with UFP ${ }^{12}$.

There is an apparent exacerbated risk of CVD because of outdoor urban air pollution, but there are also populations that are more at risk, which must be considered. For example, a study found that long-term air pollution exposes the elderly to an increased hospital admission rate for cardiac disease. ${ }^{37} \mathrm{~A}$ study focused on 


\begin{tabular}{|c|c|c|c|}
\hline $\begin{array}{c}\text { Types of } \\
\text { Outdoor Air } \\
\text { Pollution found } \\
\text { in Cities }\end{array}$ & Source/Composition & Adverse Health Effects & $\begin{array}{c}\text { WHO guideline } \\
\text { level }\end{array}$ \\
\hline $\begin{array}{l}\text { Particulate Matter } \\
2.5 \mathrm{uM} \text { or } 10 \mathrm{uM} \\
\left(\mathrm{PM}_{2.5} \text { or } \mathrm{PM}_{10}\right)\end{array}$ & $\begin{array}{l}\text { Components of sulfates, } \\
\text { nitrates, ammonia, } \\
\text { sodium chloride, black } \\
\text { carbon, mineral dust and } \\
\text { water suspended in the } \\
\text { air, often from } \\
\text { combustion }\end{array}$ & $\begin{array}{l}\mathrm{PM}_{10} \text { can enter lungs } \\
\text { through inhalation } \\
\text { causing cardiovascular } \\
\text { and respiratory problems. } \\
\mathrm{PM}_{2.5} \text { can enter lung } \\
\text { barrier and blood system } \\
\text { causing cardiovascular } \\
\text { and respiratory problems }\end{array}$ & $\begin{array}{l}\frac{\mathrm{PM}_{10}}{20 \mu \mathrm{g} / \mathrm{m}^{3} \text { annual }} \\
\text { mean } \\
50 \mu \mathrm{g} / \mathrm{m}^{3} 24 \text {-hour } \\
\text { mean } \\
\frac{\mathrm{PM}_{2.5}}{10 \mu \mathrm{g} / \mathrm{m}^{3} \text { annual }} \\
\text { mean } \\
25 \mu \mathrm{g} / \mathrm{m}^{3} 24 \text {-hour } \\
\text { mean }\end{array}$ \\
\hline $\begin{array}{l}\text { Nitrogen Dioxide } \\
\left(\mathrm{NO}_{2}\right)\end{array}$ & $\begin{array}{l}\text { Aerosols, component of } \\
\mathrm{PM}_{2.5}, \text { emission from } \\
\text { combustion for heat, } \\
\text { power, engines of vehicles } \\
\text { and ships }\end{array}$ & $\begin{array}{l}\text { Causes inflammation of } \\
\text { airways, bronchitis in } \\
\text { asthmatic children, } \\
\text { reduced lung function }\end{array}$ & $\begin{array}{l}40 \mu \mathrm{g} / \mathrm{m}^{3} \text { annual } \\
\text { mean } \\
200 \mu \mathrm{g} / \mathrm{m}^{3} 1 \text {-hour } \\
\text { mean }\end{array}$ \\
\hline $\begin{array}{l}\text { Sulfur Dioxide } \\
\left(\mathrm{SO}_{2}\right)\end{array}$ & $\begin{array}{l}\text { Produced from } \\
\text { combustion of fossil fuels } \\
\text { (coal and oil) mostly for } \\
\text { heating power of motor } \\
\text { vehicles, common } \\
\text { component of acid rain }\end{array}$ & $\begin{array}{l}\text { Reduced lung function, } \\
\text { eye irritation, } \\
\text { inflammation of } \\
\text { respiratory tract, } \\
\text { increased risk of } \\
\text { pulmonary infection, } \\
\text { increased risk of } \\
\text { cardiovascular disease }\end{array}$ & $\begin{array}{l}20 \mu \mathrm{g} / \mathrm{m}^{3} 24 \text {-hour } \\
\text { mean } \\
500 \mu \mathrm{g} / \mathrm{m}^{3} 10 \text {-minute } \\
\text { mean }\end{array}$ \\
\hline Ozone $\left(\mathrm{O}_{3}\right)$ & $\begin{array}{l}\text { Ground level component } \\
\text { of photochemical smog } \\
\text { created when sunlight } \\
\text { reacts with other air } \\
\text { pollutants }\end{array}$ & $\begin{array}{l}\text { Causes breathing } \\
\text { problems, asthma, } \\
\text { reduced lung function, } \\
\text { enhanced lung diseases }\end{array}$ & $\begin{array}{l}100 \mu \mathrm{g} / \mathrm{m}^{3} 8 \text {-hour } \\
\text { mean }\end{array}$ \\
\hline
\end{tabular}

metropolitan areas of Greece found that longterm exposure to traffic-related air pollution caused an added risk of fatal and nonfatal ischemic heart disease and stroke. Importantly, they found that this CVD risk was higher in women and younger children. ${ }^{33}$

Urban, traffic, and industrial-related air pollution is the biggest issue in large cities in Asia. ${ }^{38}$ In Tianjin, Shenyang, Taiyuan, and Rizhao, air pollution levels are significantly higher than even the upper limits of the WHO guidelines. 3920 These increases in $\mathrm{PM}_{2.5}$ are associated with higher risks of CVD mortality.
Importantly, the more significant impact on CVD mortality was associated with a longer duration of exposure. 40 Air quality has not only been associated with a decline in human health but also in food instability in China. In six sectors of China, the $\mathrm{PM}_{2.5}$ and the $\mathrm{O}_{3}$ pollutants were found to be detrimental to human health as well as crop production leading to an overall reduction in health..$^{41}$ Additionally, a study from Seoul, South Korea found that long-term exposure to $\mathrm{PM}_{2.5}$, specifically a $1 \mu \mathrm{g} / \mathrm{m}^{3}$ increase over an average of seven years caused a $36 \%$ increase in cardiovascular events ${ }^{42}$. Importantly, 
these cardiovascular events, which included heart failure, myocardial infarction, and stroke, occurred in individuals who had no previous cardiovascular issues, emphasizing the staggering implication of long-term air pollution on heart health. ${ }^{42}$

Furthermore, India has a considerably higher prevalence of elevated levels of urban air pollution. This is associated with the country's increased motor vehicle activity as well as industrialization. A group analyzed 59 independent studies of short (hours, days, weeks) and long-term (months, years) ambient air pollution cases in India. They determined that long-term air pollution was strongly associated with asthma, heart attack, cardiovascular mortality, and premature mortality. The majority of health problems related to air pollution were caused by $\mathrm{PM}_{2.5}{ }^{44}$

In the United States, outdoor air pollution has been associated with increased cardiovascular death, specifically in urbanized areas. ${ }^{45}$ A comprehensive study examined 90 U.S. cities for $\mathrm{PM}_{10}$ and found an increase in mortality, specifically cardiovascular and respiratory mortality. ${ }^{46}$ Another study analyzed 88 of the largest urban areas in the United States for over eight years and analyzed all causes of mortality. They found that variations of $\mathrm{PM}_{10}$ were attributed to cardiovascular and respiratory mortality compared to all other causes of death. ${ }^{47}$ The same group examined five outdoor air pollutants relative to mortality in 20 of the largest cities in the United States over the same eight-year period. They found that the $\mathrm{PM}_{10}$ was the air pollutant most strongly associated with cardiovascular mortality. In fact, for every $10 \mu \mathrm{g}$ per cubic meter increase in $\mathrm{PM}_{10}$, there is a rise in cardiovascular-related death. ${ }^{48}$ Another study analyzed data from 13.2 million U.S. residents within a six-mile radius of a $\mathrm{PM}_{2.5}$ monitor. They found that in eastern and central U.S. urban centers, a $10 \mu \mathrm{g}$ per cubic meter increase of $\mathrm{PM}_{2.5}$ over six years was associated with a $6.8 \%$ increase in mortality. ${ }^{49}$ Even with this information, the United States Environmental Protection Agency (US EPA) standards are not limiting enough. A study examined hospitalization and congestive heart failure cases in seven U.S. cities over 13 years. They found that even air pollution levels below the EPA standard still resulted in additional hospital admission rates for congestive heart failure in people above the age of $65 . .^{50}$

Across the globe, it is clear that increased long-term exposure to air pollution has a significant impact on cardiovascular health. However, there is still not much understood about how to reverse or lessen the adverse health effects of air pollution.

\section{Discussion}

\section{How to Reduce Long-term Air Exposure Risks in Urban Settings}

Long-term exposure in urban areas is a significant risk factor for various CVDs. The United States Environmental Protection Agency (US EPA) created an annual National Ambient Air Quality Standard (NAAQS) in 1997 specifically for $\mathrm{PM}_{2.5}$ that would require a decrease of $1 \mu \mathrm{g}$ per cubic meter in $\mathrm{PM}_{2.5}$. A study examined the rate of cardiovascular mortality based on changes in the $\mathrm{PM}_{2.5}$ before and after the changes in the NAAQS guidelines in over 180 countries across the globe over 20 years. Interestingly, they found that for every $1 \mu \mathrm{g}$ per cubic meter decrease in $\mathrm{PM}_{2.5}$ lead to about a $1.10 \%$ decrease in cardiovascular-related deaths. ${ }^{51}$

Langrish et al., found that reducing personal exposure to PM by wearing masks that have a polypropylene filter that filters airborne PM and does not change ambient gas did improve the health of patients with coronary heart disease. ${ }^{52}$ Car filters have also been suggested as a possible recirculatory way to reduce airborne nanoparticles. The filters help recirculate the air to minimize nanoparticle concentrations below dangerous levels. The filters can reduce the concentration of 
pollutants less than nanoparticle concentration accumulated after three minutes of driving in heavy traffic. ${ }^{53}$ Even low-efficiency filters have been shown to protect from traffic PM exposure effectively. ${ }^{53}$ Exhaust PM traps on specific car engines have also been successful at decreasing PM exposure. These traps have even been used as a biomarker for CVD improvement. ${ }^{54}$

As of 2019, there are studies designed to understand how outdoor air pollution affects cardiovascular health in specific populations. The Reducing Air Pollution in Detroit
Intervention Study (RAPIDS) is analyzing a senior citizen community in Detroit for CVDs, increased blood pressure, and vasoconstriction ${ }^{5554}$. This area has been strongly linked to high levels of outdoor air pollution, specifically $\mathrm{PM}_{2.5}$. The group is using low efficiency and high-efficiency air filters in various conditions to assess if they can help improve cardiovascular health outcomes for high-risk populations. ${ }^{54}$ Continued studies such as this would be beneficial for an understanding of cardiovascular global health relative to outdoor air pollution.

\section{Addressing Issues Regarding Outdoor Air Pollution}

There is a dire need for change when it comes to PM and other air pollutants. The US EPA has suggested changes in air quality standards, statewide implementation plans, and ways to reduce vehicle emissions ${ }^{56}$, but more work still needs to be done. For example, improvements have been made relative to traffic pollution through emission controls. Specifically, there are requirements for fewer tailpipe emissions as well as reduced crankcase emissions (combustion-related gases from the engine) through mandatory vehicle emission testing in the US ${ }^{25}$, however, universally these measures are still lacking.

Globally, the WHO Air Quality Guidelines (AQGs) are updated annually to be used as a baseline and reference for world leaders and lawmakers to make decisions for air quality limits and management. ${ }^{57}$ The primary air pollutants the AQGs address included the particulate matter of various sizes, ozone, nitrogen dioxide, and sulfur dioxide. More recently, the guidelines have taken the length of exposure more seriously by including the impact of the duration of exposure in the AQGs as a way to emphasize the drastic need to update laws and educate the public. ${ }^{57}$

\section{Conclusions}

Overall, the long-term exposure of outdoor ambient air pollution in urban settings is an increased hazard and risk for global health,
These guidelines are meant to aid and advise world leaders; however, the impact and use of the guidelines are not followed equally across the globe. Joss et al. discovered that air quality standards for ambient outdoor air pollutants from 170 countries out of the 194 analyzed had varied levels of air quality standards, most not complying with the WHO guidelines. Moreover, 57 countries did not have any air quality standards at all..$^{58}$ This indicated not only a need for a better global air quality plan but also a need for better universal approaches to improve air quality.

More recently, the United Nations General Assembly created the global 2030 Agenda for Sustainable Development in 2015. One of the main goals created by this group was to adequately address air pollution and emphasize the detrimental effect on human health. ${ }^{59}$ The current seventeen Sustainable Development Goals (SDGs) do not have an individual goal for air standards or air pollution. So, this 2030 Agenda was put forth to create a global air quality standard by focusing on international law about the atmosphere and global air pollution. ${ }^{59}$

specifically for cardiovascular health. There is significant evidence of the cardiovascular risk associated with outdoor air pollution in urban 
environments. Specifically, long-term exposure (more than three months) to outdoor air pollution leads to an amplified potential for a variety of CVDs and their risk factors. Cities and metropolitan areas have an increased susceptibility to the negative effects of outdoor air pollution because of added exposure to traffic and motor emission pollution, which leads to increased concentrations of dangerous air pollutants. Mechanistically, an increase in this outdoor air pollution has been shown to escalate inflammation in the heart and vasculature, which causes exacerbated effects of CVD. Yet, the detailed mechanism and side effects are still unknown.

There are still many questions that need to be answered in regards to the specific concentrations of various air pollutants and their effects on cardiovascular health, specifically in vulnerable populations worldwide. A comprehensive understanding of all the various outdoor air pollutants, their concentrations in urban environments globally, and their toxicities, would provide insight into why outdoor air pollution is so harmful in certain areas and what can be done to prevent further damage. There are still many unknowns regarding the extended exposure to outdoor air pollution on cardiovascular health, ${ }^{38} \mathrm{~A}$ better understanding of the mechanism could allow for more targeted interventions for preventing or lessening the adverse effects on human health. Finally, there is still a need for universal policies on air quality standards that are implemented and followed globally.

\section{Conflicts of Interest}

The authors have no conflicts to disclose.

\section{Statement of Contributions}

LK had the idea for the article under the guidance of HM. LK did the literature review and writing. HM provided critical revisions and oversight.

\section{References}

1. Cardiovascular diseases (CVDs). Accessed February 22, 2020. https://www.who.int/news$\mathrm{room} /$ fact-sheets/detail/cardiovascular-diseases-(cvds)

2. Shaddick G, Thomas ML, Mudu P, Ruggeri G, Gumy S. Half the world's population are exposed to increasing air pollution. Npj Clim Atmospheric Sci. 2020;3(1):1-5. doi:10.1038/s41612-020-0124-2

3. Ritchie H, Roser M. Air Pollution. Our World Data. Published online April 17, 2017. Accessed March 23, 2020. https:// ourworldindata.org/air-pollution

4. Brook RD. Cardiovascular effects of air pollution. Clin Sci. 2008;115(6):175-187. doi:10.1042/CS20070444

5. Fann N, Fulcher CM, Hubbell BJ. The influence of location, source, and emission type in estimates of the human health benefits of reducing a ton of air pollution. Air Qual Atmosphere Health. 2009;2(3):169-176. doi:10.1007/s11869-009-0044-0

6. Schwela D. Air Pollution and Health in Urban Areas. Rev Environ Health. 2011;15(1-2):13-42. doi:10.1515/REVEH.2000.15.1-2.13

7. Liang L, Gong P. Urban and air pollution: a multi-city study of long-term effects of urban landscape patterns on air quality trends. Sci Rep. 2020;10(1):18618. doi:10.1038/s41598-020-74524-9

8. D'Amato G, Cecchi L, D'Amato M, Liccardi G. Urban air pollution and climate change as environmental risk factors of respiratory allergy: an update. J Investig Allergol Clin Immunol. 2010;20(2):95-102; quiz following 102.

9. Blumenthal SJ, Kagen J. The Effects of Socioeconomic Status on Health in Rural and Urban America. JAMA. 2002;287(1):109. doi:10.1001/jama.287.1.109-JMS0102-3-1 
10. Menon P, Ruel MT, Morris SS. Socio-economic Differentials in Child Stunting are Consistently Larger in Urban than in Rural Areas. Food Nutr Bull. 2000;21(3):282-289. doi: $10.1177 / 156482650002100306$

11. Abelsohn A, Stieb DM. Health effects of outdoor air pollution. Can Fam Physician. 2011;57(8):881-887.

12. Downward GS, van Nunen EJHM, Kerckhoffs J, et al. Long-Term Exposure to Ultrafine Particles and Incidence of Cardiovascular and Cerebrovascular Disease in a Prospective Study of a Dutch Cohort. Environ Health Perspect. 2018;126(12):127007. doi:10.1289/EHP3047

13. Lin Hualiang, Guo Yanfei, Di Qian, et al. Ambient PM2.5 and Stroke. Stroke. 2017;48(5):11911197. doi:10.1161/STROKEAHA.116.015739

14. Huang J, Li G, Qian X, et al. The burden of ischemic heart disease related to ambient air pollution exposure in a coastal city in South China. Environ Res. 2018;164:255-261. doi:10.1016/j.envres.2018.02.033

15. Kim SY, Kim SH, Wee JH, et al. Short and long-term exposure to air pollution increases the risk of ischemic heart disease. Sci Rep. 2021;11(1):5108. doi:10.1038/s41598-021-84587-x

16. Weichenthal S, Hoppin JA, Reeves F. Obesity and the cardiovascular health effects of fine particulate air pollution. Obesity. 2014;22(7):1580-1589. doi:10.1002/oby.20748

17. PRISMA. Accessed November 17, 2021. http://www.prismastatement.org/PRISMAStatement/Checklist.aspx

18. An Z, Jin Y, Li J, Li W, Wu W. Impact of Particulate Air Pollution on Cardiovascular Health. Curr Allergy Asthma Rep. 2018;18(3):15. doi:10.1007/s11882-018-0768-8

19. Malik Ali O., Jones Philip G., Chan Paul S., Peri-Okonny Poghni A., Hejjaji Vittal, Spertus John A. Association of Long-Term Exposure to Particulate Matter and Ozone With Health Status and Mortality in Patients After Myocardial Infarction. Circ Cardiovasc Qual Outcomes. 2019;12(4):e005598. doi:10.1161/CIRCOUTCOMES.119.005598

20. Pope CA, Burnett RT, Thun MJ, et al. Lung cancer, cardiopulmonary mortality, and long-term exposure to fine particulate air pollution. JAMA. 2002;287(9):1132-1141. doi:10.1001/jama.287.9.1132

21. Miller KA, Sullivan JH. Long-Term Exposure to Air Pollution and Incidence of Cardiovascular Events in Women. N Engl J Med. Published online 2007:12.

22. Chuang KJ, Yan YH, Chiu SY, Cheng TJ. Long-term air pollution exposure and risk factors for cardiovascular diseases among the elderly in Taiwan. Occup Environ Med. 2011;68(1):64-68. doi:10.1136/oem.2009.052704

23. Pope CA, Burnett RT, Thurston GD, et al. Cardiovascular Mortality and Long-Term Exposure to Particulate Air Pollution: Epidemiological Evidence of General Pathophysiological Pathways of Disease. Circulation. 2004;109(1):71-77. doi:10.1161/01.CIR.0000108927.80044.7F

24. Sun Q, Wang A, Jin X, et al. Long-term Air Pollution Exposure and Acceleration of Atherosclerosis and Vascular Inflammation in an Animal Model. JAMA. 2005;294(23):3003-3010. doi:10.1001/jama.294.23.3003

25. Hoek G, Krishnan RM, Beelen R, et al. Long-term air pollution exposure and cardio- respiratory mortality: a review. Environ Health. 2013;12(1):43. doi:10.1186/1476-069X-12-43

26. Dockery DW, Pope CA, Xu X, et al. An association between air pollution and mortality in six U.S. cities. N Engl J Med. 1993;329(24):1753-1759. doi:10.1056/NEJM199312093292401

27. Laden F, Schwartz J, Speizer FE, Dockery DW. Reduction in fine particulate air pollution and mortality: Extended follow-up of the Harvard Six Cities study. Am J Respir Crit Care Med. 2006;173(6):667-672. doi:10.1164/rccm.200503-443OC

28. Sowers JR, Epstein M, Frohlich ED. Diabetes, Hypertension, and Cardiovascular Disease: An Update. Hypertension. 2001;37(4):1053-1059. doi:10.1161/01.HYP.37.4.1053 
29. Fuks Kateryna, Moebus Susanne, Hertel Sabine, et al. Long-Term Urban Particulate Air Pollution, Traffic Noise, and Arterial Blood Pressure. Environ Health Perspect. 2011;119(12):17061711. doi:10.1289/ehp.1103564

30. Schwartz J. Air Pollution and Daily Mortality: A Review and Meta Analysis. Environ Res. 1994;64(1):36-52. doi:10.1006/enrs.1994.1005

31. Zhang K, Batterman S. Air pollution and health risks due to vehicle traffic. Sci Total Environ. 2013;450-451:307-316. doi:10.1016/j.scitotenv.2013.01.074

32. Cesaroni Giulia, Badaloni Chiara, Gariazzo Claudio, et al. Long-Term Exposure to Urban Air Pollution and Mortality in a Cohort of More than a Million Adults in Rome. Environ Health Perspect. 2013;121(3):324-331. doi:10.1289/ehp.1205862

33. Katsoulis M, Dimakopoulou K, Pedeli X, et al. Long-term exposure to traffic-related air pollution and cardiovascular health in a Greek cohort study. Sci Total Environ. 2014;490:934-940. doi:10.1016/j.scitotenv.2014.05.058

34. Cai Y, Hodgson S, Blangiardo $\mathrm{M}$, et al. Road traffic noise, air pollution and incident cardiovascular disease: A joint analysis of the HUNT, EPIC-Oxford and UK Biobank cohorts. Environ Int. 2018;114:191-201. doi:10.1016/j.envint.2018.02.048

35. Beelen R, Raaschou-Nielsen O, Stafoggia M, et al. Effects of long-term exposure to air pollution on natural-cause mortality: an analysis of 22 European cohorts within the multicentre ESCAPE project. The Lancet. 2014;383(9919):785-795. doi:10.1016/S0140-6736(13)62158-3

36. Brunekreef B, Beelen RMJ, Hoek G, et al. Effects of long-term exposure to traffic-related air pollution on respiratory and cardiovascular mortality in the Netherlands: the NLCS-AIR study. Research report (Health Effects Institute). Published 2009. Accessed March 18, 2020. http://localhost/handle/1874/39242

37. Anderson HR, Atkinson RW, Bremner SA, Marston L. Particulate air pollution and hospital admissions for cardiorespiratory diseases: are the elderly at greater risk? Eur Respir J. 2003;21(40 suppl):39s-46s. doi:10.1183/09031936.03.00402203

38. Carlsten C, Rider CF. Traffic-related air pollution and allergic disease: an update in the context of global urbanization. Curr Opin Allergy Clin Immunol. 2017;17(2):85-89. doi:10.1097/ACI.0000000000000351

39. Long-term exposure to urban air pollution and lung cancer mortality: A 12-year cohort study in Northern China. Sci Total Environ. 2016;571:855-861. doi:10.1016/j.scitotenv.2016.07.064

40. Zhao L, Liang HR, Chen FY, Chen Z, Guan WJ, Li JH. Association between air pollution and cardiovascular mortality in China: a systematic review and meta-analysis. Oncotarget. 2017;8(39). doi:10.18632/oncotarget.20090

41. Gu Y, Wong TW, Law CK, et al. Impacts of sectoral emissions in China and the implications: air quality, public health, crop production, and economic costs. Environ Res Lett. 2018;13(8):084008. doi:10.1088/1748-9326/aad138

42. Kim H, Kim J, Kim S, et al. Cardiovascular Effects of Long-Term Exposure to Air Pollution: A Population-Based Study With 900845 Person-Years of Follow-up. J Am Heart Assoc. 6(11):e007170. doi:10.1161/JAHA.117.007170

43. Badami MG. Transport and Urban Air Pollution in India. Environ Manage. 2005;36(2):195-204. doi:10.1007/s00267-004-0106-x

44. Rajak R, Chattopadhyay A. Short and long-term exposure to ambient air pollution and impact on health in India: a systematic review. Int J Environ Health Res. 2019;0(0):1-25. doi:10.1080/09603123.2019.1612042

45. Young GS, Fox MA, Trush M, Kanarek N, Glass TA, Curriero FC. Differential Exposure to Hazardous Air Pollution in the United States: A Multilevel Analysis of Urbanization and Neighborhood Socioeconomic Deprivation. Int J Environ Res Public Health. 2012;9(6):2204-2225. doi:10.3390/ijerph9062204 
46. Dominici F, McDermott A, Daniels M, Zeger SL, Samet JM. Revised Analyses of the National Morbidity, Mortality, and Air Pollution Study: Mortality Among Residents Of 90 Cities. J Toxicol Environ Health A. 2005;68(13-14):1071-1092. doi:10.1080/15287390590935932

47. Dominici Francesca, McDermott Aidan, Zeger Scott L, Samet Jonathan M. National maps of the effects of particulate matter on mortality: exploring geographical variation. Environ Health Perspect. 2003;111(1):39-44. doi:10.1289/ehp.5181

48. Samet JM, Dominici F, Curriero FC, Coursac I, Zeger SL. Fine Particulate Air Pollution and Mortality in 20 U.S. Cities, 1987-1994. N Engl J Med. 2000;343(24):1742-1749. doi:10.1056/NEJM200012143432401

49. Zeger Scott L., Dominici Francesca, McDermott Aidan, Samet Jonathan M. Mortality in the Medicare Population and Chronic Exposure to Fine Particulate Air Pollution in Urban Centers (20002005). Environ Health Perspect. 2008;116(12):1614-1619. doi:10.1289/ehp.11449

50. Wellenius GA, Schwartz J, Mittleman MA. Particulate Air Pollution and Hospital Admissions for Congestive Heart Failure in Seven United States Cities. Am J Cardiol. 2006;97(3):404-408. doi:10.1016/j.amjcard.2005.08.061

51. Corrigan AE, Becker MM, Neas LM, Cascio WE, Rappold AG. Fine particulate matters: The impact of air quality standards on cardiovascular mortality. Environ Res. 2018;161:364-369. doi:10.1016/j.envres.2017.11.025

52. Langrish Jeremy P., Li Xi, Wang Shengfeng, et al. Reducing Personal Exposure to Particulate Air Pollution Improves Cardiovascular Health in Patients with Coronary Heart Disease. Environ Health Perspect. 2012;120(3):367-372. doi:10.1289/ehp.1103898

53. Pui David Y.H., Qi Chaolong, Stanley Nick, Oberdörster Günter, Maynard Andrew. Recirculating Air Filtration Significantly Reduces Exposure to Airborne Nanoparticles. Environ Health Perspect. 2008;116(7):863-866. doi:10.1289/ehp.11169

54. Morishita M, Thompson KC, Brook RD. Understanding Air Pollution and Cardiovascular Diseases: Is It Preventable? Curr Cardiovasc Risk Rep. 2015;9(6):30. doi:10.1007/s12170-015-0458-1 55. Maestas MM, Brook RD, Ziemba RA, et al. Reduction of personal PM2.5 exposure via indoor air filtration systems in Detroit: an intervention study. J Expo Sci Environ Epidemiol. 2019;29(4):484490. doi:10.1038/s41370-018-0085-2

56. US EPA O. Air Pollution: Current and Future Challenges. US EPA. Published May 27, 2015. Accessed February 22, 2020. https://www.epa.gov/clean-air-act-overview/air-pollution-current-andfuture-challenges

57. Héroux ME, Vilahur* N. Update of the World Health Organization Global Air Quality Guidelines. ISEE Conf Abstr. Published online August 17, 2016. doi:10.1289/isee.2016.3357

58. Kutlar Joss M, Eeftens M, Gintowt E, Kappeler R, Künzli N. Time to harmonize national ambient air quality standards. Int J Public Health. 2017;62(4):453-462. doi:10.1007/s00038-017-0952y

59. Lode B, Schönberger P, Toussaint P. Clean Air for All by 2030? Air Quality in the 2030 Agenda and in International Law. Rev Eur Comp Int Environ Law. 2016;25(1):27-38. doi:10.1111/reel.12151 